\title{
Towards Third-Party Audit of Corporate Social Responsibility Report: A Survey in China
}

\author{
Meng X.H. ${ }^{1, a}$, Zhu Y.L. ${ }^{1, b}$, Xu X.Y. ${ }^{1, c}$, Zhao C.Y., ${ }^{1, d}$ \\ ${ }^{1}$ School of Politics and Public Administration, Soochow University, Suzhou 215123, China \\ amengxhsuda@163.com, bhuyunlico@163.com, '819015597@qq.com, ${ }^{\mathrm{d}} 573521241 @ q q . c o m$
}

\begin{abstract}
Keywords: Third-party; Audit; Corporate social responsibility; Manufacturing listed company Abstract. In order to show their corporate social responsibility (CSR), Chinese enterprises start to publish CSR reports, however, the majority of these reports lack third-party audit and therefore are unable to be assured reliability. Using a sample of all Chinese manufacturing listed companies in the Stock "A" markets at Shanghai and Shenzhen Stock Exchange from 2010 to 2014, we investigate the status quo of listed companies' third-party audit of CSR reports (e.g., quantitative proportion, characteristics of distribution, audit institution and declarative pattern), reveal deficiencies and then provide suggestions to promote the development of third-party audit of Chinese CSR report.
\end{abstract}

\section{Introduction}

In last decade, a series of regulations were issued to strengthen enterprises to fulfill corporate social responsibility (CSR) in China. The social responsibility consciousness is rising and some enterprises published CSR reports to disclose their practices and performance. However, most of them were lack of objective third-party audit, which is the key step to assure quality of CSR reports and CSR fulfillment. Therefore, it is important to clarify status quo of third-party audits of CSR reports in China and reveal what are the main deficiencies. Only through investigation in detail can we explore appropriate countermeasures and thus promote third-party audit of CSR reports.

Recently, China's social and environmental pollution incidents have broken out frequently with large scale and great social impact, such as Zijin Mining leakage of copper acid water in 2010, Shanxi aniline spill in 2012 and Songhua River pollution incident in 2013. These events not only torture CSR regulatory system, but also further place social and environmental responsibility as the hot point in public [1]. In 2015, the explosion in Binhai industrial zone, Tianjin province, and severe smog in North China in December pushed the issue of CSR again into a cusp.

CSR report is the main document to disclose fulfillment of CSR performance, which is also important as annual report, for enterprises to disclose their annual practices in sustainability (e.g., CSR goals and strategies, actions, and social and environmental performance) [2]. It should be disclosed by way of qualitative and quantitative methods. The researchers have recognized that CSR report should be given the same importance as financial report, however, its authenticity and reliability should be also assured by the third party.

The third-party audit of CSR report has been widely concerned in developed countries. European experts believed that if CSR report gains the trust of investors, it must be done with independent audit [3]. It is pointed out that CSR report without external auditing or verifying is not much better than advertisement [4], the auditing practice director of Association of Chartered Certified Accountants (ACCA), David York argued that large numbers of organizations utilized the reports of environment, society or sustainability as a window shop decoration and posed a gesture with green and environmental friendliness [5]. Yuan (2011) also believed that Chinese CSR report should be published a statement with an independent third-party audit to assess CSR credibility [6]. Zhou (2011) put forward some suggestions about the Chinese third-party audit of CSR report from the perspective of government legislation and information disclosure system [7]. Mao (2010) pointed out that social responsibility audit in China trudged at an early stage and did not yet shape theoretical framework [8]. By reviewing the work of Chinese environmental audit, Zhang (2011) argued that environmental audit towards Chinese companies was still in its infancy and social responsibility audit reports not 
only include the information of general opinions but also disclose details with CSR advantages and disadvantages [9]. Generally, scholars believed that it is the necessary procedure for CSR report to be confirmed by third party.

\section{Study Methods and Analysis}

Data Collection and the Sample. The investigated companies are all manufacturing firms listed in the Stock "A" markets at Shanghai and Shenzhen Stock Exchanges in China [10,11]. Data on third-party audit information are abstracted using content analysis from the listed company's annual report and separate CSR reports from Websites of Shanghai and Shenzhen Stock Exchanges. Aspects of CSR information disclosure are collected from the database of China Stock Market \& Accounting Research database (CSMAR). Total 3,654 firm-year valid observations are obtained from 2010 to 2014.

Quantitative Proportion of Third-Party Audit of CSR Report. Table 1 shows that there are a large number of sampled enterprises, however, the enterprises that published CSR report are not in the majority, among of the CSR reports with third-party audit are even fewer. The proportion of CSR reports with third-party audit just maintained at $1.9 \%$ in the past five years, while the proportion for those enterprises disclosed both CSR report and third-party audit declaration is only maintained at $0.62 \%$.

It can be found that there are few numbers of CSR reports written in accordance with GRI Sustainability Reporting Guidelines, and disclose less information on the aspects of CSR system and improvements and other defects of company, but more on the aspects of stockholder's equity protection and employees' rights and interests.

Table 1. Aspects of CSR report and the number of third-party audit from 2010-2014

\begin{tabular}{lrrrrr}
\hline \multicolumn{1}{c}{ Year } & \multicolumn{1}{c}{ 2010 } & \multicolumn{1}{c}{2011} & 2012 & 2013 & 2014 \\
\hline Number of sampled listed companies & 683 & 707 & 719 & 737 & 808 \\
CSR report disclosed & 201 & 227 & 231 & 257 & 266 \\
$\quad$ Reference to GRI guidelines & 19 & 32 & 40 & 40 & 45 \\
$\quad$ Third-party audit & 1 & 4 & 8 & 3 & 7 \\
Frequencies of aspect of CSR information disclosure & & & & & \\
$\quad$ Stockholder's equity protection & 200 & 219 & 223 & 249 & 260 \\
Creditor's claim protection & 128 & 125 & 127 & 138 & 136 \\
Employees' rights and interests & 201 & 224 & 229 & 256 & 265 \\
Supplier's interests & 143 & 175 & 185 & 189 & 196 \\
Customers and consumers' interests & 197 & 222 & 220 & 251 & 258 \\
Environment and sustainable development & 197 & 226 & 228 & 255 & 261 \\
Public relations and services & 194 & 214 & 215 & 242 & 256 \\
Safety production & 178 & 195 & 206 & 225 & 237 \\
CSR system improvements & 46 & 82 & 56 & 27 & 28 \\
Other defects in the company & 40 & 32 & 27 & 25 & 27 \\
\hline
\end{tabular}

\section{Characteristics of Distribution for Listed Companies with Third-Party Audit.}

Temporal Distribution. Table 2 reports those companies accepted third-party assurance of CSR reports from 2010 to 2014. We found that those enterprises disclosed CSR reports with third-party audit seldom last CSR audit up to the five sampled years. Table 2 lists the companies coded as 600196, 600619 and 600690 will be assured by third party in the coming years after the first third-party audit. Apart from the companies coded as 600104, 600618, 601177 and 601231 passed the first third-party audit in 2014 , the rest do not continuously audit by the third party. 
Table 2. The companies disclosed CSR report with third-party audit

\begin{tabular}{cccccc}
\hline Code listed in Stock Exchange & 2010 & 2011 & 2012 & 2013 & 2014 \\
\hline 000568 & & $\sqrt{ }$ & & \\
000612 & & $\sqrt{ }$ & & \\
000800 & & $\sqrt{ }$ & & \\
600104 & $\sqrt{2}$ & $\sqrt{ }$ & $\sqrt{ }$ & $\sqrt{ }$ & $\sqrt{ }$ \\
600196 & & $\sqrt{ }$ & $\sqrt{ }$ & & \\
600600 & & & & & $\sqrt{ }$ \\
600618 & & $\sqrt{ }$ & $\sqrt{ }$ & $\sqrt{ }$ & $\sqrt{ }$ \\
600619 & & $\sqrt{ }$ & $\sqrt{ }$ & $\sqrt{ }$ & $\sqrt{ }$ \\
600690 & & & & & $\sqrt{ }$ \\
601177 & & & & & $\sqrt{ }$ \\
601231 & & & $\sqrt{ }$ & \\
601339 & 1 & 4 & 8 & 3 & 7 \\
\hline Total & & & & & \\
\hline
\end{tabular}

Regional Distribution. Table 3 presents regional distribution of companies with CSR third-party audit. It is found that in a total of 23 audited CSR reports, enterprises located in developed coastal areas is up to 20, of which Shanghai municipality accounts for the largest number, reaching 12 .

Table 3. Regional distribution of the companies with CSR third-party audit

\begin{tabular}{lccccc}
\hline Province & 2010 & 2011 & 2012 & 2013 & 2014 \\
\hline Shanghai & 1 & 2 & 2 & 2 & 5 \\
Shandong & 0 & 2 & 2 & 1 & 1 \\
Sichuan & 0 & 0 & 1 & 0 & 1 \\
Henan & 0 & 0 & 1 & 0 & 0 \\
Jilin & 0 & 0 & 1 & 0 & 0 \\
Zhejiang & 0 & 0 & 1 & 0 & 0 \\
\hline Total & 1 & 4 & 8 & 3 & 7 \\
\hline
\end{tabular}

Industrial Distribution. Table 4 reports the industrial distribution of companies with CSR audit. We can find a clear upward trend in the industries of C35 (general purpose machinery) and C37 (transport equipment), and unstable trend in the industries of C15 (beverages), C17 (textile), C32 (pressing of ferrous metals) and C39 (electrical machinery), and relatively stable trend is the industry of $\mathrm{C} 27$ (medicines). It is unable to observe the trend in the industries of $\mathrm{C} 26$ (raw chemical materials) and C40 (computers and telecom), because CSR report with third-party audit only first appeared in 2014.

Table 4. Industrial distribution of all the companies with CSR third-party audit from 2010-2014

\begin{tabular}{clcccccc}
\hline $\begin{array}{c}\text { Industrial } \\
\text { classification } \\
\text { code }\end{array}$ & \multicolumn{1}{c}{ Industry } & 2010 & 2011 & 2012 & 2013 & 2014 & Trend \\
\hline C15 & Beverages & 0 & $11.11 \%$ & $18.18 \%$ & 0 & 0 & \\
C17 & Textile & 0 & 0 & $20.00 \%$ & 0 & 0 & \\
C26 & Raw chemical materials & 0 & 0 & 0 & 0 & $4.35 \%$ & \\
C27 & Medicines & $4.55 \%$ & $4.00 \%$ & $5.26 \%$ & $4.35 \%$ & $4.35 \%$ & \\
C32 & Pressing of ferrous metals & 0 & 0 & $5.88 \%$ & 0 & 0 & \\
C35 & General purpose machinery & 0 & 0 & $9.09 \%$ & $8.33 \%$ & $13.33 \%$ & \\
C37 & Transport equipment & 0 & 0 & $6.25 \%$ & $5.88 \%$ & $5.56 \%$ & \\
C39 & Electrical machinery & 0 & $11.11 \%$ & $6.67 \%$ & 0 & $6.25 \%$ & \\
C40 & Computers and telecom & 0 & 0 & 0 & 0 & $2.86 \%$ & \\
\hline
\end{tabular}


Third-Party Audit Institution and Pattern of Declaration. As shown in Table 5-6, we can find that there are different types of audit institutions as the third party to assure or declare on CSR reports, such as certification authority, industry associations as well as accounting firms. However, at present, China has no relevant laws and regulations to stipulate the type of third-party audit institution for CSR

Table 5. The third-party audit institutions and patterns of audit declaration

\begin{tabular}{|c|c|c|}
\hline Year & Code & Name of audit institution \\
\hline 2010 & 600196 & $\begin{array}{l}\text { Standards of General Technical } \\
\text { Services co., Ltd. Shanghai branch } \\
\text { (SGS) }\end{array}$ \\
\hline \multirow[t]{5}{*}{2011} & 600196 & SGS \\
\hline & 600600 & $\begin{array}{l}\text { China Brewing Industry Association, } \\
\text { beer branch (CBIA) }\end{array}$ \\
\hline & 600619 & Shanghai Audit Center of Quality \\
\hline & 600690 & China Household Electrical \\
\hline & & Appliances Association (HEAA) \\
\hline \multirow[t]{2}{*}{2012} & 000568 & $\begin{array}{l}\text { China Certification \& Accreditation } \\
\text { Institute (CCAI) }\end{array}$ \\
\hline & 000612 & $\begin{array}{l}\text { China Quality Certification Center } \\
(\mathrm{CQC})\end{array}$ \\
\hline
\end{tabular}

000800 Ruihua Certificate Public Accountants Only stated that "To further perfect internal control system, our company employed Ruihua Certificate Public

Accountants as the third-party audit to improve internal control in 2012."

600196 SGS

Declaration of SGS

600600 China Brewing Industry Association, Evaluation and suggestion of China Brewing Industry beer branch

Association, beer branch.

600619 Shanghai Audit Center of Quality

SAC's audit report; System (SAC)

600690 China Household Electrical Appliances Association (HEAA)

601339 Bureau verltas;

2013600196 SGS China textile industry association

Certificate of CSR evaluation.

HEAA's evaluation report;

Assessment report of He Q., head of securities and futures institute, Central University of Finance and Economics. Only stated that "CSR report has verified by the third-party, Bureau verltas and China Textile Industry Association."

600619 Shanghai Audit Center of Quality Declaration of SGS.

SAC's audit report; System (SAC)

600690 China Household Electrical Certificate of CSR evaluation. Appliances Association (HEAA)

Evaluation report of HEAA.

2014600104 Deloitte \& Touche Certificate Public Accountants

600196 SGS

600618 Shanghai Audit Center of Quality System (SAC)

600619 Shanghai Audit Center of Quality System (SAC)

600690 China Household Electrical Appliances Association (HEAA)

601177 Pan-China Certificate Public Accountants

601231 SGS (Taiwan Ltd.)

Only stated that "the company hired Deloitte \& Touche Certified Public Accountants to validate the report in 2014." Declaration of SGS.

SAC's audit report.

SAC's audit report;

Certificate of CSR evaluation.

Evaluation report of HEAA.

Pan-China Certificate Public Accountants provided the internal audit report (No. 2229, 2015).

Only Stated that "To improve transparency and reliability, CSR report will be guaranteed by third party, SGS (Taiwan Ltd.), and meet standards of GRI G4 \& AA1000 AS 2008." 
Table 6. Type of institution as third-party audit in each year

\begin{tabular}{ccccc}
\hline Year & Certification authority (\%) & Industrial associations $(\%)$ & Accounting firms (\%) & Total (\%) \\
\hline 2010 & $1(100.00 \%)$ & $0(0.00 \%)$ & $0(0.00 \%)$ & $1(100 \%)$ \\
2011 & $2(50.00 \%)$ & $2(50.00 \%)$ & $0(0.00 \%)$ & $4(100 \%)$ \\
2012 & $4(50.00 \%)$ & $3(37.50 \%)$ & $1(12.50 \%)$ & $8(100 \%)$ \\
2013 & $2(66.67 \%)$ & $1(33.33 \%)$ & $0(0.00 \%)$ & $3(100 \%)$ \\
2014 & $4(57.14 \%)$ & $1(14.29 \%)$ & $2(28.57 \%)$ & $7(100 \%)$ \\
\hline
\end{tabular}

reports. Due to different situations (e.g., stakeholders, cost pressure, social responsibility consciousness), CSR reports of Chinese listed manufacturing enterprises were declared by diverse third-party institutions, and the authority of these institutions as third-party audit is questionable. In addition, the majority of 23 companies demonstrated third-party declaration reports or evaluation at the end of CSR report, and there are a few companies simply describing in a few words to mention the audit by third institutions.

\section{Discussions and Conclusions}

Chinese listed companies selectively disclosed CSR reports and voluntarily open the practices of CSR activities, and therefore, it is hard to guarantee reliability of CSR report without adequate external independent supervision. In 2015, Chinese Academy of Social Science published China Corporate Social Responsibility Report, revealing that the CSR index of the top 300 Chinese enterprises has increased but the growth is declining. The level of CSR activity is in its infancy, although Chinese enterprises paid more attention to CSR and put into practice. However, almost all the CSR reports are unverified by the third party in the past five years. The ratio of CSR reports of listed companies with third-party audit only is $0.50 \%$ in $2010,1.76 \%$ in $2011,3.46 \%$ in $2012,1.17 \%$ in 2013 and $2.63 \%$ in 2014, showing that few CSR reports receive the third-party audit.

The regional distribution of third-party audit of CSR report varies significantly. In coastal developed areas, especially in Shanghai, the awareness of enterprises conduct third-party audit of CSR reports more than other areas. Therefore, the location of enterprise is one of the important factors affecting CSR audit.

There are diverse declarations and different certification institution as well as unfixed format of third-party audit of CSR reports in China. As a result, the authority of CSR reports would not be guaranteed. Together with the fact that CSR third-party audit has not improved greatly in recent years, it is indicated that Chinese firms' awareness of third-party audit of the CSR reports is particularly inadequate.

The stakeholders should give more pressure on CSR audit, for those with more demands of CSR (e.g., stockholders, the government, the public and media) should have a greater impact on CSR audit. However, we must face the fact that the appeal of the public limitedly threats enterprise in China and social and environmental NGO has no enough power to play the role of the third hand besides government and market. With regard to the media as a particular stakeholder, although the new media network buzzing (e.g., micro blog) and speeding up the information dissemination, the news of recent environmental events indicated that the media only focused on in a short time and shifted to other hot spots of society, thus resulting in a lack of follow-up reports and even the unknown solutions. Therefore, the demand pressure on CSR audit is not obvious.

Also, the history of study on social and environmental audit is short, and the extensive researches were conducted only in the past decade. Future research on social and environment audit should more closely focus on the latest practice of international social and environmental accounting, integrating environmental science, accounting and audit into CSR evaluation, assurance and audit.

The results have several potential implications for regulators and management practice.

Firstly, it is urgent to enact standard criteria to guide CSR third-party verification, because the issued laws and regulations upon CSR in China have played a positive role to stimulate CSR practices 
increasing. Mandatory CSR audit, rather than voluntary reporting assurance, is necessary in the context of China, which should enforce the regulations covering a wide range of Chinese companies. Therefore, mandatory standards and guidelines for CSR audit can guarantee reliability of information disclosure. The mainstream guidelines of third-party audit on CSR report in western developed countries are AA1000 and ISAE3000 assurance standard. Both of them have their own advantages, that is, AA1000 provides the entire framework for social responsibility auditing, focusing on stakeholder requirements and attitudes, while ISAE3000 abolishes the restrictions on report styles, focusing on the importance, relevance and integrity of CSR report. It is indispensable to be a set of sound, effective and practical guidelines in the setting of China, supporting for the level of audit quality, defining audit function, responsibilities, as well as communication between enterprises and audit institutions.

Secondly, enterprise is the core CSR actor and the level of awareness of social responsibility is crucial. Strengthening managers' CSR awareness is as important as emphasizing necessity of CSR third-party audit. The CSR disclosure does not mean issuing a simple report, which should include CSR daily operation management, relations with internal and external stakeholders, as well as financial information. Thus, CSR auditing procedure requires investing more time, human resource and financial cost. It may be a burden for firms in the early stage and should be given more support. For the large-scale enterprises and state-owned enterprises should play a leading role in industry.

Thirdly, the NGOs and media are also the important stakeholders to promote the CSR audit. As non-profit civil organizations, NGOs can act as third-party participants in assurance of CSR report. The power of Chinese NGO, such as environmental NGO, is relatively weak. Adopted the experience of developed countries, guide and power given to the NGO can increase the effect of external monitor. Media that transmits information between various stakeholders has a major impact on the corporate social image. Only through the joint efforts of government, enterprises, NGOs, media and the public, it is possible to set up the effective mechanism and procedure of CSR third-party audit to assure authority of CSR report.

\section{Acknowledgements}

This research is financially supported by the National Natural Science Foundation of China (No. 71573185), Ministry of Education of Humanities and Social Science Project (No. 14YJC630100) and College Graduate Academic Initiative and $18^{\text {th }}$ Extra-Curricular Research of Soochow University (No. KY2016248B).

\section{References}

[1] X.H. Meng, S.X. Zeng, C.M. Tam and X.D. Xu: Bus. Ethics. Vol. 114 (2013), p. 341-353

[2] Information on http://www.kpmg.com/Global/en/Pages/default.aspx

[3] H.J. Homer: Bus. Horizons Vol. 44 (2001), p. 29-36

[4] K. Hammond, M. Samantha: Account. Forum Vol. 28 (2004), p. 61-79

[5] Information on http://www.accglobal.com/ members/publications

[6] Y. Yun: Commun. Finan. Account. Vol. 3 (2011), p. 25-27

[7] H.N. Zhou: F Changchun Univ. Vol. 21 (2011), p. 30-46

[8] H.T. Mao: Audit Econ. Vol. 25 (2010), p. 47-53

[9] C.J. Zhang, L.H. Chen and S.C. Huang: Chin. Pop. Resour. Environ. Vol. 21 (2011), p. 35-40

[10] N. Darnall, I. Henriques and P. Sadorsky: Manage. Stud. Vol. 47 (2010), p. 1072-94

[11] S.X. Zeng, X.D. Xu and Z.Y. Dong: Clean. Prod. Vol. 18 (2010), p. 1142-48 